\title{
Prevalence of the Most Frequent Neuropsychiatric Diagnoses in Hospitalized SARS-CoV-2 Patients Evaluated by Liaison Psychiatry: Cross-Sectional Study
}

\author{
Prevalência dos Diagnósticos Neuropsiquiátricos Mais Frequentes \\ em Pacientes Internados com SARS-CoV-2 Avaliados por \\ Psiquiatria de Ligação: Estudo Transversal
}

Luís Afonso FERNANDES $\square^{1}$, Catarina GARCIA RIBEIRO ${ }^{2}$, Marisa MARTINS ${ }^{3}$, Inês FIGUEIREDO ${ }^{1}$, Manuel DIAS ${ }^{1}$, João FACUCHO ${ }^{4}$, Joana CARRENO ${ }^{5}$, Inês GUERRA ${ }^{6}$, Carlos VIEIRA ${ }^{1}$, Catarina OLIVEIRA ${ }^{7}$, Alice LUÍS ${ }^{1}$, Teresa MAIA Acta Med Port 2022 Jun;35(6):425-432 $\cdot$ https://doi.org/10.20344/amp.16410

\section{ABSTRACT}

Introduction: The SARS-CoV-2 infection has been associated with the acute onset of mental and behavioural symptoms and psychiatric disorders. The aim of this study was to assess the prevalence of the different neuropsychiatric diagnoses in hospitalized patients with SARS-CoV-2 infection assessed by Liaison Psychiatry.

Material and Methods: We performed a cross-sectional study in a hospital near Lisbon, Portugal. We reviewed the electronic health records from all inpatients with a positive SARS-CoV-2 RT-PCR test that were assessed by the Liaison Psychiatry Unit (LPU) between February and December 2020. We reviewed relevant sociodemographic and clinical data, including 15 neuropsychiatric symptoms. The prevalence of psychiatric disorders was our main outcome. We also explored differences between two groups: patients with delirium (delirium group) and patients without delirium (no delirium group).

Results: We included 46 cases [Age: median $=67$ years; interquartile range $(I Q R)=24)$ ], with $60.9 \%$ male individuals. Delirium was the most frequent diagnosis in our sample $(43.5 \%)$, followed by major depressive disorder $(21.7 \%)$. Patients with delirium were more likely to suffer from COVID-19 symptoms (delirium: 19/20, 95\%; no delirium: 14/26, 53.8\%; $p=0.02$ ), and to have a longer time interval between a positive SARS-CoV-2 RT-PCR test and an evaluation by the LPU (delirium: median = 16.5 days, IQR = 16; no delirium: median $=8$ days, IQR $=16.3 ; p=0.045)$. Agitation $(52.2 \%)$ and cognitive symptoms $(47.8 \%)$ were the most reported neuropsychiatric symptoms.

Conclusion: We found a high prevalence of delirium in our sample. This finding is in line with recent literature concerning hospitalized COVID-19 patients The higher frequency of COVID-19 symptoms found in the delirium group suggests a possible association between symptomatic SARS-CoV-2 infection and delirium onset.

Keywords: COVID-19; Delirium; Mental Health Services; Psychiatry; Referral and Consultation

\section{RESUMO}

Introdução: A infecção por SARS-CoV-2 tem sido associada ao desenvolvimento agudo de sintomas mentais e comportamentais e perturbações psiquiátricas. O objetivo deste estudo foi determinar a prevalência de diferentes diagnósticos neuropsiquiátricos em doentes hospitalizados com infeção SARS-CoV-2 avaliados pela Psiquiatria de Ligação.

Material e Métodos: Realizámos um estudo transversal num hospital da região de Lisboa, em Portugal. Revimos os processos clínicos dos pacientes internados com um resultado RT-PCR positivo para SARS-CoV-2 avaliados pela Unidade de Psiquiatria de Ligação (UPL) entre fevereiro e dezembro de 2020. Incluímos dados sociodemográficos e clínicos, incluindo quinze sintomas neuropsiquiátricos. A incidência de diferentes diagnósticos psiquiátricos foi o nosso outcome primário. Explorámos também diferenças entre dois grupos: doentes com delirium e doentes sem delirium.

Resultados: Incluímos 46 casos [Idade: mediana = 67 anos; amplitude interquartil (AIQ) = 24)], a maioria do sexo masculino $(60,9 \%)$. Delirium foi o diagnóstico mais frequente na nossa amostra (43,5\%), seguido de perturbação depressiva major $(21,7 \%)$. Doentes com delirium tiveram uma prevalência maior de sintomas de COVID-19 (delirium: 19/20, 95\%; sem delirium: 14/26, 53,8\%; $p=0,02$ ), bem como um intervalo de tempo mais longo entre um teste RT-PCR SARS-CoV-2 positivo e observação pela UPL (delirium: mediana = $16,5, \mathrm{AIQ}=16$; sem delirium: mediana $=8, \mathrm{AIQ}=16,3 ; p=0,045)$. Agitação $(52,2 \%)$ e sintomas cognitivos $(47,8 \%)$ foram os sintomas neuropsiquiátricos mais relatados.

Conclusão: Foi encontrada na nossa amostra uma elevada prevalência de delirium. Este resultado está de acordo com literatura recente relativamente a doentes internados com COVID-19. A maior frequência de sintomas COVID-19 no grupo com delirium sugere uma possível associação entre infecção sintomática por SARS-CoV-2 e o desenvolvimento desta síndrome.

Palavras-chave: COVID-19; Delírio; Encaminhamento e Consulta; Psiquiatria; Serviços de Saúde Mental

\footnotetext{
1. Departamento de Saúde Mental. Hospital Prof. Doutor Fernando Fonseca. Lisboa. Portugal.

2. Centro Hospitalar Universitário de Lisboa Central. Lisboa. Portugal.

3. Serviço de Psiquiatria. Hospital Distrital de Santarém. Santarém. Portugal.

4. Departamento de Psiquiatria e Saúde Mental. Hospital de Cascais. Cascais. Portugal.

5. Unidade de Saúde Familiar Monte da Luz. Agrupamento de Centros de Saúde Sintra. Sintra. Portugal.

6. Unidade de Saúde Familiar Mactamã. Agrupamento de Centros de Saúde Sintra. Sintra. Portugal.

7. Departamento de Psiquiatria e Saúde Mental. Unidade Local de Saúde de Castelo Branco. Castelo Branco. Portugal.

$\square$ Autor correspondente: Luís Afonso Fernandes. lafonsocunha@gmail.com

Recebido/Received: 18/04/2021 - Aceite/Accepted: 13/09/2021 - Publicado Online/Published Online: 16/02/2022 - Publicado/Published: 01/06/2022 Copyright $\odot$ Ordem dos Médicos 2022
} 


\section{INTRODUCTION}

The severe acute respiratory syndrome coronavirus 2 (SARS-CoV-2) was first identified in humans in Wuhan province, China, on the $19^{\text {th }}$ December 2019. ${ }^{1}$ In March 2020, the World Health Organization announced the coronavirus outbreak to be a pandemic and on the $21^{\text {st }}$ December 2021, over 273 million cases have been identified worldwide. ${ }^{2}$

The disease caused by SARS-CoV-2 in humans was named COVID-19. The virus is transmitted through the respiratory tract, primarily affecting this organ system. However, other parts of the body, including the central nervous system (CNS), are also frequently affected, either through direct viral lesion or via systemic inflammation triggered by SARS-CoV-2. ${ }^{3}$ Accordingly, an increasing body of evidence supports the existence of a high prevalence of neuropsychiatric symptoms associated with SARS-CoV-2 acute infection. ${ }^{4}$ Altered mental status, including disorders of the consciousness content (i.e., delirium, confusion) and consciousness level (i.e., somnolence, stupor, and coma), affects $7.5 \%$ to $65 \%$ of all patients hospitalized with COVID-19..$^{5-7}$ Delirium is a non-specific syndrome of acute or subacute onset and fluctuating course characterized by disorder of consciousness, attention, cognition, and behaviour. ${ }^{8}$ COVID-19 related delirium is thought to be associated with different factors, including metabolic and inflammatory cascade derangements that are correlated with the severity of the systemic illness, infectious spread to the brain, and CNS inflammation by dysregulation of cytokine activation. ${ }^{9}$ latrogenic (e.g., sedation and prolonged ventilation) and environmental factors (e.g., social isolation) might also play an important role in the development of delirium in hospitalized patients infected with SARS-CoV-2. ${ }^{10}$

An association between SARS-CoV-2 and other neuropsychiatric disorders has so far been less frequently reported. However, in a mixed neurological and neuropsychiatric cohort of COVID-19 patients, $18.4 \%$ of all cases with SARS-CoV-2 infection had a primary psychiatric diagnosis, including psychosis, dementia, amongst other psychiatric disorders. ${ }^{4}$

The onset of psychiatric disorders in the aftermath of SARS-CoV-2 infection was explored in population studies published in the previous year. Taquet and colleagues reported an increased prevalence of new-onset psychiatric diagnosis in the first three months after SARS-CoV-2 infection, with the greatest hazard ratio for anxiety disorders, insomnia, and dementia. ${ }^{11}$ In the UK, a deterioration of population mental health was also described after the initial impact of the COVID-19 pandemic, particularly in women, 18 to 34-year-olds, and people living with children. ${ }^{12}$

In Portugal, the first case of COVID-19 was diagnosed on the $2^{\text {nd }}$ March $2020 .{ }^{13}$ Our institution, a general hospital responsible for the inpatient treatment of individuals infected with SARS-CoV-2 across two Portuguese municipalities (Amadora and Sintra) in the Lisbon Metropolitan Area, adapted its care delivery in the framework of a very high incidence of SARS-CoV-2 infections. In this context, the Liaison Psychiatry Unit (LPU) started to assist patients admitted to the
COVID-19 medical wards presenting with mental and behavioural symptoms. Patients who were hospitalized because of a psychiatric disorder and had a SARS-CoV-2 infection were admitted to the same COVID-19 wards and received psychiatric care delivered by the LPU.

In the present study, we intended to characterize the population of patients with SARS-CoV-2 infection hospitalized in our institution. Our main outcome was to determine the frequency of different psychiatric disorders. Since we expected to find a high prevalence of delirium, we also explored potential differences between patients presenting with and without delirium.

\section{MATERIAL AND METHODS}

\section{Study design, settings, and participants}

We followed the 'Strengthening the Reporting of Observational Studies in Epidemiology guidelines' (STROBE).$^{14}$ We performed the current cross-sectional study-in a hospital that serves the Portuguese municipalities of Amadora and Sintra (population: 556864 people). We used a convenience sample, by including all patients evaluated by the LPU with a positive real time (RT)-PCR SARS-CoV-2 test that were admitted to a COVID-19 medical ward due to nonpsychiatric complaints between the $26^{\text {th }}$ February 2020 and the $31^{\text {st }}$ December 2020. All tests were performed using samples from the upper respiratory tract. Only patients with a positive test in the context of the current admission were included in the study. All included cases were evaluated by the LPU (either by direct observation or consultation). Patients whose clinical records did not contain information regarding the outcomes under study and patients admitted due to a psychiatric disorder were excluded from our study.

\section{Instruments and variables}

We used Soarian ${ }^{\circledR}$ software to access electronic clinical records. Different authors registered the retrieved data in a digital spreadsheet (Microsoft Excel ${ }^{\circledR}$ ) according to the study protocol. To increase inter-observer reliability, the authors held periodic meetings, retrieved data in pairs, and, when needed, discussed specific cases. Variables with more than $50 \%$ of missing values were not included in the analysis.

We collected a set of predefined categorical and continuous variables, including:

- Sociodemographic data: sex; age; marital status; occupational status (including if the patient was a healthcare professional); and years of education.

- Clinical data: psychiatric personal and family history; risk factors for severe COVID-19, as defined by the Centers for Disease Control and Prevention (CDC) (i.e., severe cardiovascular disease; cancer; organ transplantation; obesity; sickle cell anaemia; chronic kidney disease; and diabetes) ${ }^{15}$; presence of COVID-19 symptoms (i.e. fever, cough, and dyspnoea); Charlson comorbidity index $(\mathrm{CCl})$ total score, which is a method used to predict mortality by weighting 
medical comorbidities $(\mathrm{CCl}=0$, estimated 10-year survival $=100 \% ; \mathrm{CCI}>6$, estimated 10 -year survival $=0 \% ; \mathrm{CCl}$ maximum score $=37)^{16}$; interval between the positive RT-PCR SARS-CoV-2 test and evaluation by Liaison Psychiatry (in days); length of hospital stay (in days); and admission to the intensive care unit (ICU) during the study.

- Clinical outcomes: psychiatric diagnosis attributed by the LPU according to the chapter five of the International Statistical Classification of Diseases and Related Health Problems, version 10 (ICD-10); presence of delirium (i.e., if the patient suffered from delirium, as defined by ICD-10, during the admission); type of delirium (i.e., hypoactive; hyperactive; and mixed); neuropsychiatric symptoms presented by patients [one open-answer variable and 15 binary (yes/no) variables encompassing the following predetermined symptoms: cognitive dysfunction (for example, in attention, memory, language, visuospatial function, or executive function); altered consciousness; psychomotor agitation; psychomotor retardation; depressed mood; emotional lability; irritability; pressured speech; suicidal ideation; euphoria; delusions; auditory hallucinations; other hallucinations; anxiety; and insomnia] ${ }^{17,18}$; and clinical outcome (i.e., death; discharged; lost to follow-up).

Our main outcome was the prevalence of psychiatric diagnosis attributed by the LPU. As a secondary outcome, we explored sociodemographic and clinical differences between patients with delirium (delirium group) and patients without delirium (no delirium group).

\section{Ethical considerations}

The present study received approval from the Ethics Committee of Hospital Fernando Fonseca EPE. The inclusion and exclusion criteria followed specific criteria, ensured adherence to bioethical principles and privacy of confidential user data. Considering that this is a clinical record-review based study, with low risk of breach of confidentiality, absence of clinical risks for the participants, and major potential benefit to public health, we obtained an excuse for the need of informed consent. To ensure anonymization of data, we assigned to each case an individual study number. Anonymized data was recorded on a digital spreadsheet encrypted with a password. All documents will be destroyed within five years.

\section{Statistical analysis}

We performed the statistical analysis using Microsoft Excel $^{\otimes}$ and IBM Statistical Package for the Social Sciences $^{\circledR}$ (SPSS), version 25. We used standard descriptive summaries (i.e., median, interquartile range (IQR), average, and standard deviation for continuous variables; and absolute and relative frequencies for categorical variables) to summarize sociodemographic and clinical variables and outcomes. We used a visual method and the Shapiro-Wilk test to assess normality. To compare categorical variables, we used the chi square or the Fisher's exact tests. When normality was asserted, we used the $t$-test to compare categorical variables with continuous variables. When normality was not asserted, we used the Mann-Whitney test. We performed a logistic regression for each variable of interest, considering delirium as the dependent variable. We included any statistically significant variable retrieved in the previous regression in a model with delirium as the dependent

Table 1 - Demographic characteristics of patients with SARS-CoV-2 infection evaluated by Liaison Psychiatry

\begin{tabular}{|c|c|c|c|c|}
\hline & \multicolumn{3}{|c|}{ No. (\% within the group) } & \multirow[b]{2}{*}{$p$-value } \\
\hline & $\begin{array}{c}\text { Total } \\
(n=46)\end{array}$ & $\begin{array}{c}\text { Delirium } \\
(n=20)\end{array}$ & $\begin{array}{l}\text { No delirium } \\
(n=26)\end{array}$ & \\
\hline Female sex & $18(39.1)$ & $8(40.0)$ & $10(38.5)$ & $0.916^{* *}$ \\
\hline Age, median (IQR) & $67(24.0)$ & $72.5(26.0)$ & $64.5(22.5)$ & $0.206^{\ddagger}$ \\
\hline \multicolumn{5}{|l|}{ Relationship status } \\
\hline Married & $21(53.8)$ & $8(50.0)$ & $13(56.5)$ & \multirow{3}{*}{$0.688^{* *}$} \\
\hline Single/divorced/ widowed & $18(39.1)$ & $8(50.0)$ & $10(43.5)$ & \\
\hline Unknown & 7 & 4 & 3 & \\
\hline \multicolumn{5}{|c|}{ Autonomy in activities of daily living } \\
\hline Absent & $5(10.9)$ & $3(15.0)$ & $2(7.7)$ & \multirow{3}{*}{$0.717^{* *}$} \\
\hline Partial & $9(19.6)$ & $4(20.0)$ & $5(19.2)$ & \\
\hline Full & $32(69.6)$ & $13(65.0)$ & $19(73.1)$ & \\
\hline \multicolumn{5}{|l|}{ Employment status } \\
\hline Active* & $9(20.9)$ & $2(11.1)$ & $7(28.0)$ & \multirow{4}{*}{$0.261^{* *}$} \\
\hline Unemployed & $7(16.3)$ & $3(16.7)$ & $4(16.0)$ & \\
\hline Retired & $27(62.8)$ & $13(72.2)$ & $14(56.0)$ & \\
\hline Unknown & 3 & 2 & 1 & \\
\hline
\end{tabular}


variable, while controlling for sex and age. We performed a post-hoc power calculation using a standardized calculator. ${ }^{19}$ For all analyses, $p<0.05$ was considered statistically significant.

\section{RESULTS}

We identified 56 cases with a positive RT-PCR SARS-CoV-2 test that were evaluated by the LPU during the timeframe of the study. One patient was excluded because he had a positive test that was not related to the current admission and nine because their admission was primarily motivated by a psychiatric disorder (bipolar disorder, $\mathrm{n}=2$; depressive episode, $\mathrm{n}=3$; unspecified mood disorder, $n=1$; acute and transient psychotic disorder, $n=1$; unspecified nonorganic psychosis, $n=1$; adjustment disorder, $n=1)$. Forty-six cases were included in the final analysis.

\section{Sociodemographic and clinical data}

Sociodemographic data is summarized in Table 1. The median age was 67 years $(I Q R=24)$, with twenty $(43.5 \%)$ patients being younger than 65 years old. Sex distribution was asymmetric, with a male predominance $(60.9 \%)$. Years of education was not included in the analysis because of a high proportion of missing values (> 50\%).

Most cases had at least one risk factor for severe COVID-19 disease (71.7\%), which are described in Table 2. We found high $\mathrm{CCl}$ scores in our sample, with $28.3 \%$ of cases having an overall score higher than 6 (estimated 10 -year survival $=0 \%$ ). Nevertheless, most patients were autonomous prior to their admission (69.9\%).

Table 2 - Clinical characteristics and outcomes of patients with SARS-CoV-2 infection evaluated by Liaison Psychiatry

\begin{tabular}{|c|c|c|c|c|}
\hline & \multicolumn{3}{|c|}{ No. (\% within the group) } & \multirow[b]{2}{*}{$p$-value } \\
\hline & $\begin{array}{l}\text { Total } \\
(n=46)\end{array}$ & $\begin{array}{l}\text { Delirium } \\
(n=20)\end{array}$ & $\begin{array}{l}\text { No delirium } \\
(n=26)\end{array}$ & \\
\hline \multicolumn{5}{|l|}{ Risk factors for COVID-19 } \\
\hline Cardiovascular disease $\mathrm{s}^{\S}$ & $18(39.1)$ & $7(35.0)$ & $11(42.3)$ & $0.615^{* *}$ \\
\hline Cancer & $6(13.0)$ & $2(10.0)$ & $4(15.4)$ & $0.684^{* *}$ \\
\hline Organ transplant & $0(0)$ & $0(0)$ & $0(0)$ & \multirow{3}{*}{$0.373^{*}$} \\
\hline Obesity & $13(28.3)$ & $7(35.0)$ & $6(23.0)$ & \\
\hline Sickle cell anaemia & $0(0)$ & $0(0)$ & $0(0)$ & \\
\hline COPD & $6(13.0)$ & $2(10.0)$ & $4(15.4)$ & $0.684^{* *}$ \\
\hline CKD & $8(17.4)$ & $3(15.0)$ & $5(19.2)$ & $0.511^{* *}$ \\
\hline Diabetes & $14(30.4)$ & $5(25.0)$ & $9(34.6)$ & $0.535^{* *}$ \\
\hline Any risk factor $\S$ & $33(71.7)$ & $16(80.0)$ & $18(69.2)$ & $0.410^{* *}$ \\
\hline \multicolumn{5}{|c|}{ Charlson Comorbidity Index (CCI), CCI score (estimated 10-year survival) } \\
\hline $0(100 \%)$ & $6(13.0)$ & $2(10.0)$ & $4(15.4)$ & \multirow{8}{*}{$0.644^{+\dagger}$} \\
\hline $1(98 \%)$ & $4(8.7)$ & $1(5.0)$ & $3(11.5)$ & \\
\hline $2(96 \%)$ & $3(6.5)$ & $2(10.0)$ & $1(3.9)$ & \\
\hline $3(77 \%)$ & $7(15.2)$ & $3(15.0)$ & $4(15.4)$ & \\
\hline $4(53 \%)$ & $4(8.7)$ & $3(15.0)$ & $1(3.9)$ & \\
\hline $5(21 \%)$ & $5(10.9)$ & $2(10.0)$ & $3(11.5)$ & \\
\hline $6(2 \%)$ & $4(8.7)$ & $3(15.0)$ & $1(3.9)$ & \\
\hline$>6(0 \%)$ & $13(28.3)$ & $4(20.0)$ & $9(34.6)$ & \\
\hline Psychiatric history & $23(50.0)$ & $10(50.0)$ & $13(50.0)$ & $1^{* *}$ \\
\hline COVID-19 symptoms" & $33(71.7)$ & $19(95.0)$ & $14(53.8)$ & $0.02^{* *}$ \\
\hline ICU admission ${ }^{\dagger}$ & $15(32.6)$ & $9(45.0)$ & $6(23.1)$ & $0.116^{* *}$ \\
\hline $\begin{array}{l}\text { Days between SARS-CoV-2 positive test } \\
\text { and LP evaluation, median (IQR) }\end{array}$ & $14(19.3)$ & $16.50(16.0)$ & $8(16.5)$ & $0.045^{\ddagger}$ \\
\hline Length of hospital stay median (IQR) & $28(34.5 \theta)$ & $35(34.0)$ & $23(36.5)$ & $0.370^{\ddagger}$ \\
\hline \multicolumn{5}{|l|}{ Outcomes } \\
\hline Death & $5(10.9)$ & $3(15.0)$ & $2(7.7)$ & $0.640^{t+}$ \\
\hline Discharged & $40(87.0)$ & $17(85.0)$ & $23(88.5)$ & $1^{\text {tt }}$ \\
\hline Lost to follow-up & $1(2.17)$ & $0(0)$ & $1(3.8)$ & $1^{\text {t† }}$ \\
\hline
\end{tabular}

¥¥: risk factors for severe COVID-19 illness as defined by CDC in March $2020^{15}$; §: severe cardiovascular disease, including congestive heart failure, coronary artery disease or cardiomyopathy; § §: presence of any of the previous risk factors; ॥: cough, dyspnoea, and fever; †: admission to intensive care unit (ICU) during hospitalisation; **: chi-square test; ††: Fisher's Exact test; ¥: Mann-Whitney test

COPD: chronic obstructive pulmonary disease; CKD: chronic kidney disease; IQR: Inter-Quartile Range; LP: Liaison Psychiatry 
Interestingly, $50 \%$ of the patients had a personal psychiatric history, including: mood disorders (F30 - F39, 17.4\%); organic mental disorder (F00 - F09, 13.1\%); schizophrenia, schizotypal and delusional disorders (F20 - F29, 8.7\%); and mental and behavioural disorders due to psychoactive substance use (F10 - F19, 6.3\%).

Most patients had COVID-19 symptoms (71.7\%), while the remaining were admitted in the context of other medical and surgical problems. Fifteen (32.6\%) patients were treated in the ICU during their admission. In Table 2, we describe the median length of stay and time interval between positive RT-PCR SARS-CoV-2 test and Liaison Psychiatry evaluation.

\section{Clinical outcomes}

Delirium was the most frequent diagnosis in our sample (43.5\%), followed by major depressive disorder (single episode or recurrent) $(21.7 \%)$, and adjustment disorder and acute stress reactions (21.8\%). The diagnoses according to ICD-10 are summarized in Table 3.

Regarding neuropsychiatric symptoms, agitation $(52.2 \%)$, cognitive symptoms $(47.8 \%)$, and insomnia $(41.3 \%)$ were the most frequently reported symptoms upon psychiatric evaluation (Table 4). In contrast, we found a relatively low frequency of symptoms such as euphoria $(2.2 \%)$, pressure of speech $(6.5 \%)$, suicidal thoughts $(4.5 \%)$ and psychotic symptoms, including hallucinations or delusions (6.5\% to $8.7 \%)$.

Regarding the inter-group analysis (detailed in Table 2), we found that patients with delirium had a higher prevalence of COVID-19 symptoms (delirium: 19/20; 95\%; no delirium: $14 / 26,53.8 \% ; p=0.02$ ). The delirium group also had a longer interval between the positive RT-PCR SARS-CoV-2 test

Table 3 - Main diagnosis attributed by Liaison Psychiatry

\begin{tabular}{lc}
\hline Diagnosis (ICD-10; F01-F99) & No. (\%) \\
\hline F00 Dementia in Alzheimer Disease & $1(2.2)$ \\
F03 Unspecified dementia & $1(2.2)$ \\
F05 Delirium due to known physiological condition" & $20(43.5)$ \\
Hyperactive delirium & $12(60.0)$ \\
Hypoactive delirium & $3(15.0)$ \\
Mixed delirium & $5(25.0)$ \\
F10 Alcohol related disorders & $3(6.5)$ \\
F20 Schizophrenia & $1(2.2)$ \\
F22 Delusional disorders & $1(2.2)$ \\
F30 Manic episode & $1(2.2)$ \\
F32 and F33 Major depressive disorder & $10(21.7)$ \\
F40 Phobic anxiety disorders & $1(2.2)$ \\
F41 Other anxiety disorders & $1(2.2)$ \\
F43 Reaction to severe stress. and adjustment disorders & $10(21.8)$ \\
No diagnosis & $1(2.2)$ \\
Other & $1(2.2)$ \\
\hline
\end{tabular}

II Delirium frequency was reached by combining two variables (ICD-10 diagnosis and presence of delirium) and evaluation by Liaison Psychiatry compared to the group without delirium (delirium: median $=16.5$ days, $I Q R=16$; no delirium: median $=8$ days, IQR $=16.25 ; p=0.045)$. No other variables were significantly different between these two groups. However, we found a trend concerning ICU admission, which was more frequent in the delirium group (delirium: 11/20, 55\%; no delirium: 6/26, 23.1\%; $p=0.116$ ). We should also point out that five patients $(10.9 \%)$ died during the data analysis and that a higher frequency of deaths was found in the delirium group (delirium: $3 / 20,15 \%$; no delirium: $2 / 26.7 .7 \% ; p=0.430$ ). Notably, the delirium group had a longer length of hospital stay, however this difference was not statistically significant (delirium: 35 days; IQR $=34$; no delirium: 23 days; IQR 36.50; $p=0.370$ ).

We performed a logistic regression to ascertain the effect of each of the variables of interest on the likelihood of having delirium. The raw odds ratios (OR) are described in Appendix 1, Table 1 (Appendix 1: https://www.actamedicaportuguesa.com/revista/index.php/amp/article/view/16410/ Appendix_01.pdf). Only the presence of COVID-19 symptoms was associated with delirium [raw OR = 16.29; $95 \%$ $\mathrm{Cl}(1.89,140.32) ; p=0.01]$. This association remained significant after adjusting for age and sex with patients with COVID-19 symptoms being 15.8 times more likely to exhibit delirium compared to those without the same symptoms [95\% Cl (1.68, 146.92); Nagelkerke R2 = 28.4\%; HosmerLemeshow test $=0.865 ; p=0.016]$.

Finally, the post-hoc power calculation returned low values for all variables, except for COVID-19 symptoms (see Appendix 1, Table 2; Appendix 1: https://www.actamedicaportuguesa.com/revista/index.php/amp/article/view/16410/ Appendix_01.pdf).

\section{DISCUSSION}

Almost half of the patients evaluated by Liaison Psychiatry suffered from delirium. This finding is consistent with recent studies reporting a high prevalence of delirium, confusion, and cognitive symptoms in COVID-19 samples. Arbelo and colleagues described a similar but slightly lower rate of delirium (35.2\%) in a cohort of patients referred to Liaison Psychiatry in a tertiary hospital in Spain. ${ }^{20}$

Importantly, impaired consciousness seems to be common during COVID-19 inpatient treatment, affecting 7.5\% of all patients and $14.8 \%$ of those with severe disease. ${ }^{5}$ Different studies suggest that the prevalence of altered mental status is higher in some age groups and settings, namely in older patients attending the emergency department $(28 \%),{ }^{6}$ patients assisted in a neuropsychiatric setting (25\%), ${ }^{2}$ and those admitted to the ICU $(65 \%) .{ }^{21}$ In our sample, $55 \%$ of patients with delirium were admitted to the ICU compared to $23.1 \%$ of those without delirium. However, this difference was not statistically significant $(p=0.116)$.

Worthy of note, we found an increased rate of delirium $(43.4 \%)$, agitation $(52 \%)$ and altered consciousness $(32.6 \%)$ compared to what was usually reported by the LPU before the onset of COVID-19. A cross-sectional study carried out in our hospital concluded that acute confusion and 
Table 4 - Neuropsychiatric symptoms assessed by Liaison Psychiatry

\begin{tabular}{|c|c|c|c|c|}
\hline \multirow[b]{2}{*}{ Symptoms } & \multicolumn{3}{|c|}{ No. (\% within the group) } & \multirow[b]{2}{*}{$p$-value } \\
\hline & $\begin{array}{c}\text { Total } \\
(n=46)\end{array}$ & $\begin{array}{l}\text { Delirium } \\
(n=20)\end{array}$ & $\begin{array}{l}\text { No delirium } \\
(n=26)\end{array}$ & \\
\hline $\begin{array}{l}\text { Any cognitive symptom or } \\
\text { altered consciousness }\end{array}$ & $23(50.0)$ & $17(85.0)$ & $6(30.8)$ & $<0.001^{* *}$ \\
\hline Cognitive dysfunction & $22(47.8)$ & $16(80.0)$ & $6(23.1)$ & $<0.001^{* *}$ \\
\hline Altered consciousness & $15(32.6)$ & $12(60.0)$ & $3(11.5)$ & $0.001^{* *}$ \\
\hline Any psychomotor symptom & $29(63.0)$ & $20(100.0)$ & $9(34.6)$ & $<0.001^{* *}$ \\
\hline Psychomotor agitation & $24(52.2)$ & $19(95.5)$ & $5(19.2)$ & $<0.001^{* *}$ \\
\hline Psychomotor retardation & $10(21.7)$ & $5(25.5)$ & $5(19.2)$ & $0.726^{\dagger \dagger}$ \\
\hline Any affective symptom & $27(58.7)$ & $9(45.0)$ & $18(69.0)$ & $0.098^{* *}$ \\
\hline Depressed mood & $16(34.8)$ & $3(15.0)$ & $13(50.0)$ & $0.013^{* *}$ \\
\hline Emotional lability & $10(21.7)$ & $2(10.0)$ & $8(30.8)$ & $0.154^{t+}$ \\
\hline Irritability & $9(19.6)$ & $5(25.0)$ & $4(15.4)$ & $0.472^{\dagger+}$ \\
\hline Pressured speech & $3(6.5)$ & $1(5.0)$ & $2(7.7)$ & $1^{t \dagger}$ \\
\hline Suicidal thoughts & $2(4.4)$ & $0(0.0)$ & $2(7.7)$ & $0.498^{\dagger \dagger}$ \\
\hline Euphoria & $1(2.1)$ & $0(0.0)$ & $1(3.9)$ & $1^{t+t}$ \\
\hline Any psychotic symptom & $10(21.7)$ & $7(35.0)$ & $3(11.5)$ & $0.077^{+\dagger}$ \\
\hline Delusions & $9(19.6)$ & $6(30.0)$ & $3(11.5)$ & $0.490^{\dagger+}$ \\
\hline Auditory hallucinations & $3(6.5)$ & $2(10.0)$ & $1(3.8)$ & $0.572^{t \dagger}$ \\
\hline Other hallucinations & $4(8.7)$ & $3(15.0)$ & $1(3.8)$ & $0.303^{t+}$ \\
\hline Anxiety & $14(30.4)$ & $2(10.0)$ & $12(46.2)$ & $0.008^{* *}$ \\
\hline Insomnia & $19(41.3)$ & $11(55.0)$ & $8(30.8)$ & $0.098^{* *}$ \\
\hline Other symptoms $s^{\text {Tा }}$ & $3(6.5)$ & $0(0.0)$ & $3(11.5)$ & $0.246^{t \dagger}$ \\
\hline
\end{tabular}

**: Chi-squared test; ††: Fishers Exact test; ๆाT: Symptoms registered in an open-ended field, including anhedonia, apathy, mutism, and anorexia

agitation represented only $12.9 \%$ of referrals to the LPU in a 12-month period. ${ }^{22}$ Likewise, a Liaison-Psychiatry study with 318 patients developed before the COVID-19 pandemic reported a $10.4 \%$ prevalence of delirium. ${ }^{23}$ Passos et al further reported an increase of delirium and dementia diagnoses made by Liaison Psychiatry after the onset of COVID-19. ${ }^{24}$

Major depressive disorder (21.7\%) and adjustment disorders $(21.7 \%)$ were also common in our sample. However, the occurrence of depression and adjustment disorders was similar to what was reported in other Liaison Psychiatry studies developed during ${ }^{24}$ and before ${ }^{23}$ COVID-19 pandemic. On the other hand, we identified a remarkably low prevalence of mental and behavioural disorders due to use of alcohol (6.5\%) and no cases of mental and behavioural disorders due to use of other psychoactive substances. Likewise, the frequency of severe mental illnesses, such as schizophrenia (4.8\%) and bipolar disorder $(0 \%)$, was surprisingly low, particularly when compared with the prevalence found by other authors during ${ }^{20}$ and before ${ }^{23,24}$ the COVID-19 pandemic. Hospital admission due to a psychiatric disorder was defined by us as an exclusion criterion, which likely explains the low occurrence of severe mental illnesses. Albeit the low frequency of severe mental illness found, we should take into consideration that this population may probably have a higher relative risk of poor COVID-19-related outcomes, including death. ${ }^{25}$
In our sample, patients suffering from hallmark COVID-19 symptoms (i.e., fever, cough, and dyspnoea), regardless of age and sex, were 15.8 times more likely to exhibit delirium compared to those suffering from asymptomatic SARS-CoV-2 infection. This finding suggests that COVID-19, rather than asymptomatic infection, is associated with delirium onset in inpatient settings. We hypothesised that disease severity could be a risk factor for delirium in the studied population, hence the inclusion of ICU admission as a surrogate variable. However, we recognize that this might not be the best surrogate marker, as ICU admission is independently associated with both severe COVID-19 and delirium. In future studies, authors should consider the inclusion of other surrogate markers for disease severity, such as oxygen saturation and need for oxygen therapy or ventilation.

Risk factors for severe COVID-19 were present in $71.9 \%$ of patients, which is in line with previous studies that reported an high frequency of medical comorbidities in hospitalized patients with COVID-19. ${ }^{26}$ Surprisingly, the occurrence of any or a specific medical comorbidity, $\mathrm{CCl}$ scores, and age did not correlate with delirium in our study. The former are traditional risk factors for delirium, ${ }^{8}$ but they were equally distributed in delirium and no delirium groups. The posthoc power calculation performed showed that our study's sample size was probably too small to detect significant differences between groups. We predict that a larger sample 
would allow the identification inter-group differences, thus clarifying the relationship between the variables included and delirium onset.

Finally, the evaluation by Liaison Psychiatry of patients with delirium was delayed when compared with patients without delirium. This finding could be accounted by the prevalence of patients with COVID-19 symptoms in this group, which require more intensive medical care and have a higher risk of suffering from impaired consciousness levels in the early phases of the admission, hence postponing the intervention by Liaison Psychiatry.

Our study showed that delirium is often diagnosed by Liaison Psychiatry in patients with SARS-CoV-2 infection admitted for inpatient treatment. This information is important for departments to adapt their standard of care during pandemic times. Indeed, admission to COVID-19 wards is usually associated with a wide range of environmental risk factors for delirium (e.g., impaired communication due to personal protection equipment use by healthcare professionals). At the same time, protective factors (e.g., social contacts, that are reduced due to visiting restrictions) are hampered in this context. These factors reinforce the importance of adapting delirium prevention strategies, as proposed by LaHue and colleagues. ${ }^{27}$ Other studies have evaluated how to best treat delirium associated with COVID-19, ${ }^{9}$ highlighting relevant learning points that should be taken into account when making clinical decisions and incorporated in local training programs. Lastly, hospitals and other healthcare providers could implement systematic screening of delirium to improve its detection in COVID-19 wards and enhance early intervention.

We recognize the following additional limitations of our study: we used a convenience and non-randomized sample, with enrichment of severe cases (i.e., SARS-CoV-2 infection cases in need of hospital treatment and with psychiatric symptoms that required specialized intervention); we did not identify the cases observed in-person by the LPU; missing data, albeit low, led to the exclusion from analysis of one variable; inter-rater reliability was not evaluated using standardized methods; raters were not blinded for the diagnosis; one case was lost to follow-up; and we did not include a control group.

The findings of this study could have implications for the clinical care of COVID-19 patients and may be used to inform the development of guidelines, increase the clinical suspicion of secondary mental disorders and to implement protocols or both non-pharmacological and pharmacological specific measures to prevent and treat these disorders.

One challenge of treating COVID-19 patients stems from the barriers to an effective communication, the cornerstone of interventions to prevent and treat delirium. Liaison Psychiatry teams, by sharing their communication expertise and skills, are in a pivotal position to contribute towards improving communication in these wards. This can lead to improvements in the care delivered to patients and their families and as well as to an increase in the sense of efficacy of all intervening healthcare professionals.

\section{CONCLUSION}

We found a high prevalence of delirium in our sample. This finding is in line with recent literature concerning hospitalized COVID-19 patients.

\section{ACKNOWLEDGEMENTS}

We thank the Liaison Psychiatry Unit team for the work developed and help provided in the last year.

We thank Dr Patrícia Soares and Dr Vanessa Carvalho for their help in revising the manuscript.

\section{AUTHORS CONTRIBUTION}

LAF, CGR, MM: Conception of the protocol, data acquisition and analysis, draft and critical review of the manuscript.

IF: Data acquisition, draft and critical review of the manuscript.

MD: Draft and critical review of the manuscript.

JF: Data acquisition and analysis, draft and critical review of the manuscript.

JC, IG: Conception of the protocol, data acquisition.

$\mathrm{CV}$ : Conception of the protocol, data interpretation, draft and critical review of the manuscript.

CO: Conception of the protocol, draft and critical review of the manuscript.

$A L$ : Conception of the protocol, critical review of the manuscript.

TM: Conception of the research protocol and paper; organization of the research; data interpretation; critical review of the paper; approved the final version.

\section{PROTECTION OF HUMANS AND ANIMALS}

The authors declare that the procedures were followed according to the regulations established by the Clinical Research and Ethics Committee and to the Helsinki Declaration of the World Medical Association updated in 2013.

\section{DATA CONFIDENTIALITY}

The authors declare having followed the protocols in use at their working center regarding patients' data publication.

\section{COMPETING INTERESTS}

LAF: Chair of Neuropsychopharmacology Working Group of the EFPT and member of EFPT Controlling Co mittee. Received support for attending scientific meetings from Janssen-Cilag Farmacêutica, and Lundbeck Portugal.

CGR; MM, IF, MD, JC, CV, CO, AL, IG: None

JF: Received support for attending the World Congress of Psychiatry in 2021 and the European Psychiatric Association Congress in 2021 from Janssen Pharmaceutical. Received support for attending the Congresso Nacional de Psiquiatria em 2021 and-Congresso de Ligação e Psiquiatria Psicosomática in 2021 by Lundbeck Pharmaceutical. Note: All payments have been made directly to the organization of the events and no payment has been directly issued to the author. 
TM: Received grants from Janssen to fund researcher's initiative study ("Are anomalous self-experiences predictive of Schizophrenia in children of parents with mental illness?") and Fundação Calouste Gulbenkian on behalf of Semente Project.

\section{REFERENCES}

1. Li Q, Guan X, Wu P, Wang X, Zhou L, Tong Y, et al. Early transmission dynamics in Wuhan, China, of novel coronavirus-infected pneumonia. N Engl J Med. 2020;382:1199-207.

2. World Health Organization. COVID-19 weekly epidemiological update. 2021 [cited 2021 Dec]. Available from: https://www.who.int/ publications/m/item/weekly-epidemiological-update-on-covid-19---21december-2021.

3. Gouveia CC, Campos L. Coronavirus disease 2019: clinical review. Acta Med Port. 2020;33:505-11.

4. Varatharaj A, Thomas N, Ellul MA, Davies NW, Pollak TA, Tenorio EL, et al. Neurological and neuropsychiatric complications of COVID-19 in 153 patients : a UK-wide surveillance study. Lancet Psychiatry. 2020;7:87582.

5. Mao L, Jin $\mathrm{H}$, Wang $\mathrm{M}$, $\mathrm{Hu} \mathrm{Y}$, Chen $\mathrm{S}, \mathrm{He} \mathrm{Q}$, et al. Neurologic manifestations of hospitalized patients with coronavirus disease 2019 in Wuhan, China. JAMA Neurol. 2020;77:683-90.

6. Kennedy M, Helfand BK, Gou RY, Gartaganis SL, Webb M, Moccia $\mathrm{JM}$, et al. Delirium in older patients with COVID-19 presenting to the emergency department. JAMA Netw Open. 2020;3 e2029540..

7. Rebora P, Rozzini R, Bianchetti A, Blangiardo P, Marchegiani A, Piazzoli $A$, et al. Delirium in patients with SARS-CoV-2 infection : a multicenter study. J Am Geriatr Soc. 2021;69:293-9.

8. Cerejeira J, Mukaetova-Ladinska EB. A clinical update on delirium : from early recognition to effective management. Nurs Res Pract. 2011:2011:875196.

9. Baller EB, Hogan CS, Fusunyan MA, Ivkovic A, Luccarelli JW, Madva $E$, et al. Neurocovid: pharmacological recommendations for delirium associated with COVID-19. Psychosomatics. 2020;61:585-96.

10. Kotfis K, Roberson SW, Wilson JE, Dabrowski W, Pun BT, Ely EW. COVID-19 : ICU delirium management during SARS-CoV-2 pandemic. Critical Care. 2020;24:176.

11. Taquet M, Luciano S, Geddes JR, Harrison PJ. Bidirectional associations between COVID-19 and psychiatric disorder: retrospective cohort studies of 62354 COVID-19 cases in the USA. Lancet Psychiatry. 2021;8:130-40.

12. Pierce M, Hope H, Ford T, Hatch S, Hotopf M, John A, et al. Mental health before and during the COVID-19 pandemic : a longitudinal probability sample survey of the UK population. Lancet Psychiatry. 2020;7:883-92.

13. Direção Geral da Saúde. Comunicado número C160_75_v1: Casos de infeção por novo Coronavírus (COVID-19). [cited 2020 Dec 28]. Available from: https://covid19.min-saude.pt/wp-content/uploads/2020/03/ Atualiza\%C3\%A7\%C3\%A3o-de-02032020-1728.pdf

14. von Elm E, Altman DG, Egger M, Pocock SJ, Gøtzsche PC,

\section{FUNDING SOURCES}

This study did not receive any grant or funding from public, commercial, or non-profit sector.

Vandenbroucke JP. The strengthening the reporting of observational studies in epidemiology (STROBE) statement: guidelines for reporting observational studies. J Clin Epidemiol. 2008;61:344-9.

15. Center for Disease Control and Prevention. Scientific evidence for conditions that increase risk of severe illness. 2020. [2020 Mar 01]. Available from: https://www.cdc.gov/coronavirus/2019-ncov/need-extraprecautions/evidence-table.html.

16. Charlson M, Szatrowski TP, Peterson J, Gold J. Validation of a combined comorbidity index. J Clin Epidemiol. 1994;47:1245-51.

17. Casey P, Kelly B. Fish's clinical psychopathology. Cambridge: Cambridge University Press; 2007.

18. Oyebode F. Sim's symptoms in the mind: textbook of descriptive psychopathology. $5^{\text {th }}$ ed. Amsterdam: Elsevier; 2015.

19. Kane SP. Post. ClinCalc. [cited 2021 Sep 04]. Available from: https:// clincalc.com/stats/Power.aspx.

20. Arbelo N, López-Pelayo H, Sagué M, Madero S, Pinzón-Espinosa J, Gomes-da-Costa S, et al. Psychiatric clinical profiles and pharmacological interactions in COVID-19 inpatients referred to a consultation liaison psychiatry unit : a cross-sectional study. Psychiatr Q. 2021; 92:1021-33

21. Helms J, Kremer S, Merdji H, Clere-Jehl R, Schenck M, Kummerlen $\mathrm{C}$, et al. Neurologic features in severe SARS-CoV-2 infection. N Engl J Med. 2020;382:2268-70.

22. Luís A, Sampaio I, Mendes S, Neves R, Cardoso G. Confusion/agitation in medical inpatients referred to CL Psychiatry. J Psychosom Res. 2008;64:662.

23. Oliveira S, Pires Z, Santos N. Um ano de Psiquiatria de Ligação num Hospital geral. Psilogos. 2008;5:16-29.

24. Passos F, Constante M, Delgado A, Heitor MJ. Changes in patients characteristics and service provision in liaison psychiatry during the COVID-19 pandemic. BJPsych Open. 2021;7:S341-2.

25. Maripuu M, Bendix M, Öhlund L, Widerström M, Werneke U. Death associated with coronavirus (COVID-19) infection in individuals with severe mental disorders in Sweden during the early months of the outbreak-an exploratory cross-sectional analysis of a populationbased register study. Front Psychiatry. 2021;11:1538.

26. Wiersinga WJ, Rhodes A, Cheng AC, Peacock SJ, Prescott HC Pathophysiology, transmission, diagnosis, and treatment of coronavirus disease 2019 (COVID-19): a review. JAMA. 2020;324:782-93.

27. LaHue SC, James TC, Newman JC, Esmaili AM, Ormseth CH, Ely EW. Collaborative delirium prevention in the age of COVID-19. J Am Geriatr Soc. 2020;68:947-9. 